\title{
Right Renal Artery
}

National Cancer Institute

\section{Source}

National Cancer Institute. Right Renal Artery. NCI Thesaurus. Code C52740.

An artery arising from the aorta that supplies the right kidney. 